\title{
A model of dry matter distribution in cassava (Manihot esculenta Crantz)
}

\author{
B. W. J. Boerboom
}

Department of Tropical Crop Science, Agricultural University, Wageningen, the Netherlands

Accepted: 24 January 1978

Key words: cassava, Manihot esculenta Crantz, dry matter distribution, harvest index, root-shoot ratio

\section{Summary}

Results of an experiment were analysed and data obtained from literature were recalculated to determine which factors control the dry matter distribution in the cassava plant. Under given conditions for long periods, possibly for the storage life of cassava, the distribution of dry matter over storage roots and shoot proved to be constant. Based on this finding, a model was developed and two parameters were introduced: ESRP, efficiency of the plant at producing storage roots; ISS, initial plant weight at which storage root production starts. The model was used to visualize genetic differences and the effect of environmental conditions on dry matter distribution. The relation between harvest index and ESRP was discussed. It is recommended that ESRP is used instead of harvest index as a selection trait. Selection material on ESRP can be screened rather early in the growth cycle as storage root weight is linearly related to plant weight.

\section{Introduction}

In order to understand how different factors control the yield of storage roots of cassava, both their effect on the growth of the plant as a whole and on the translocation of photosynthetic products to the storage roots have to be known. Translocation controls how much of the plant will be ultimately harvested (harvest index) and is thus of great importance for yield. As distribution of dry matter over various parts of the cassava plant had never been studied systematically, such an investigation was undertaken with the help of a method described by van de Sande Bakhuyzen (1937) and Brouwer (1962). By plotting the weight of one organ of a plant against that of whole plant or against the weight of another organ, these authors showed that during the growth cycle of plants there are long periods when distribution is constant. 
It was assumed that their method of investigating dry matter distribution patterns would provide more information on the relation between shoot and root growth, on the length of time during which such a relationship might last and probably lead to a better understanding of factors controlling the harvest index. This parameter has become increasingly popular with plant breeders, physiologists and agronomists working in cassava (CIAT, 1975).

Hence in a field trial plants were harvested and separated in different parts, several times during the first 10 months of the growth cycle and the results were analysed. Additionally, the literature was searched and relevant data were recalculated. Ultimately this study led to the development of a model by which the dry matter distribution in the cassava plant could be described.

\section{Data obtained from experimentation and literature study}

\section{Experiment at the University of the West Indies}

Materials and methods. The trial was undertaken on an experimental field (clay loam) of the University of the West Indies (UWI) in Trinidad. Stem cuttings (length $10 \mathrm{~cm}, \varnothing 14 \mathrm{~mm}$ ) of $\mathrm{cv}$. TO $1-72$ (UWI selection) were planted, $90 \mathrm{~cm}$ apart in the row and between rows, $2 \mathrm{~cm}$ below the soil at an angle of $45^{\circ}$. Planting took place on 12 September 1974. Shortly after planting, all shoots except one of the planting sets were removed. Ten weeks after planting, each plant received $57 \mathrm{~g}$ of a compound fertilizer $\left(12: 12: 17: 2=\mathrm{N}: \mathrm{P}_{2} \mathrm{O}_{5}: \mathrm{K}_{2} \mathrm{O}: \mathrm{MgO}\right)$ including trace elements. Four replicates, each consisting of four plants, were harvested every 4 weeks between 17 and 41 weeks after planting. At each harvest, plants were separated into stem cutting (= planting material), thin fibrous roots $(\emptyset \geqslant 5 \mathrm{~mm})$, storage roots $(\varnothing>5 \mathrm{~mm})$, stem, petioles and leaf blades, their dry

weight of storage roots $(\mathrm{g})$

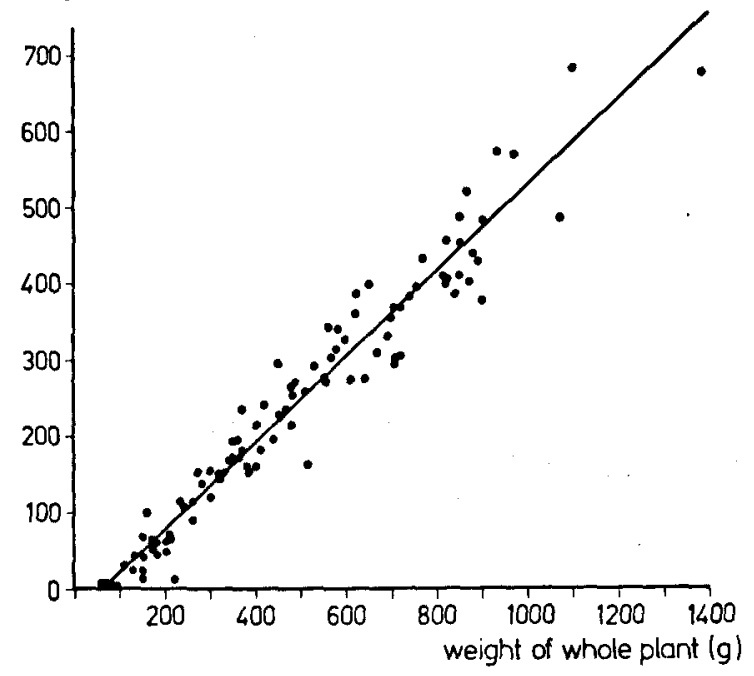

0

Fig. 1. Relationship between dry weight of whole plant $x$ and dry weight of storage roots $y$ for individual plants of a field trial at UWI: $y=0.56 x-34 ; r^{2}=0.96 ; n=112$. 


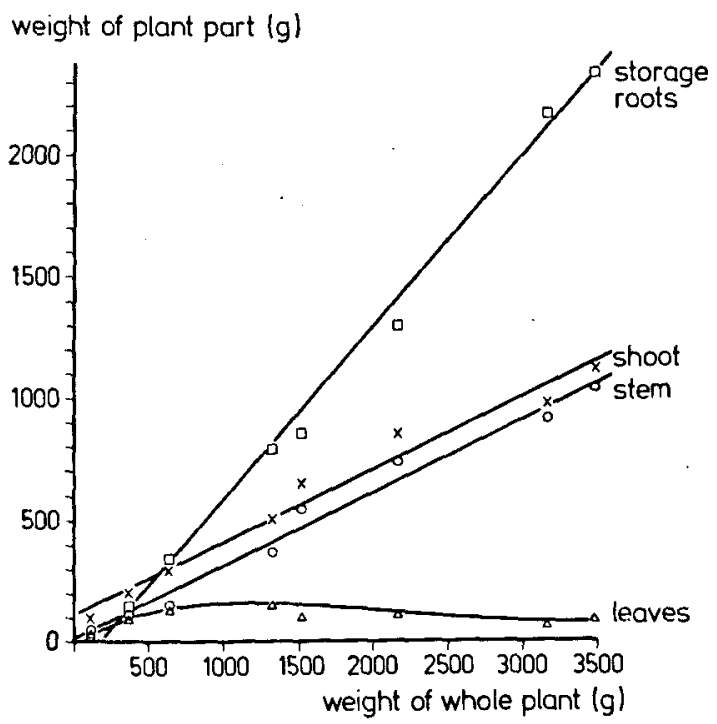

Fig. 2. Relationships between dry weight of whole plant $x$ and dry weight of plant parts $y$ for cv. SPP. (After Nijholt, 1935).

$\square$ storage roots: $\mathrm{y}=0.70 \mathrm{x}-118$; $\mathrm{s}_{\mathrm{b}}=0.02 ; \mathrm{r}^{2}=1.00 ; \mathrm{n}=8$.

$x$ shoot: $\quad y=0.30 x+118$;

$\mathrm{s}_{\mathrm{b}}=0.02 ; \mathrm{r}^{2}=0.97 ; \mathrm{n}=8$.

stem: $\quad y=0.30 x+18$;

$\mathrm{s}_{\mathrm{b}}=0.02 ; \mathrm{r}^{2}=0.98 ; \mathrm{n}=8$.

weights were determined. By the time of the first harvest all plants had storage roots.

Results. Fig. 1 is a plot of weight of storage roots y against weight of whole plant $\mathrm{x}$ for all 112 plants, harvested between 17 and 41 weeks after planting. The relationship between $\mathrm{y}$ and $\mathrm{x}$ is linear: $\mathrm{y}=0.56 \mathrm{x}-34 ; \mathrm{r}^{2}=0.96$. This linearity suggests that bulking rate (increase in weight of storage roots per unit time per unit area) kept pace with rate of crop growth (increase in weight of whole plant per unit time per unit area). Thus both bulking rate and crop growth rate were calculated for all time intervals and replicates and indeed the correlation between these two rates was high $\left(\mathrm{r}^{2}=0.94\right)$.

Also relationships for weight of stem or shoot (stem + leaves present at harvest) with whole plant were linear ( $\mathrm{r}^{2}$ in both cases for 112 plants 0.93$)$.

Relationships for organs, which constitute only a minor part of the total dry weight of an older cassava plant, such as leaves (present at harvest), stem cutting (= planting material) and thin fibrous roots $(\leqslant 5 \mathrm{~mm}$ ), with whole plant were not linear (low $\mathrm{r}^{2}$ ) and were not investigated in detail.

\section{Literature study}

To test the validity of the findings on linearity, the literature was searched and data of Nijholt (1935), Cours (1951), Hunt (1974), Cock (1976) and G. H. de Bruijn (pers. commun., 1977) were recalculated.

Nijholt (1935) investigated the growth of cassava between 9 and 63 weeks after planting. His results are given in Fig. 2 where the weight of the different plant parts is plotted against that of whole plant. This graph shows that dry matter 
distribution for storage roots, stem and shoot (= stem + leaves) is constant as in my experiment. The relation between leaf weight, which was not corrected for leaf fall, and weight of whole plant is more complicated (curved line).

Cours (1951) studied the growth of cassava plants for two years and his results show an S-shape relation between time and weight of whole plant, and between time and starch weight, both for the first and for the second year of growth (Fig. 3A). In Fig. 3B starch is plotted against whole plant, for both years the relation between them is linear: the slopes of regression lines of year one and two do not differ significantly. So starch deposition follows a rather fixed pattern throughout time.

Also from other data (Hunt, 1974; Cock, 1976; G. H. de Bruijn, pers. comm., 1977), on weight of whole plant and that of storage roots for several harvests throughout rather long periods, linear relationships between whole plant and storage roots were computed and $\mathrm{r}^{2}$ values were never below 0.95 .

\section{Conclusion}

My results and those of other authors show that for a long period, and possibly for the storage life of cassava, the distribution of dry matter over the main organs (storage roots, stem or shoot) is constant. From this conclusion it follows that the relationship between weight of shoot and that of storage roots is linear.
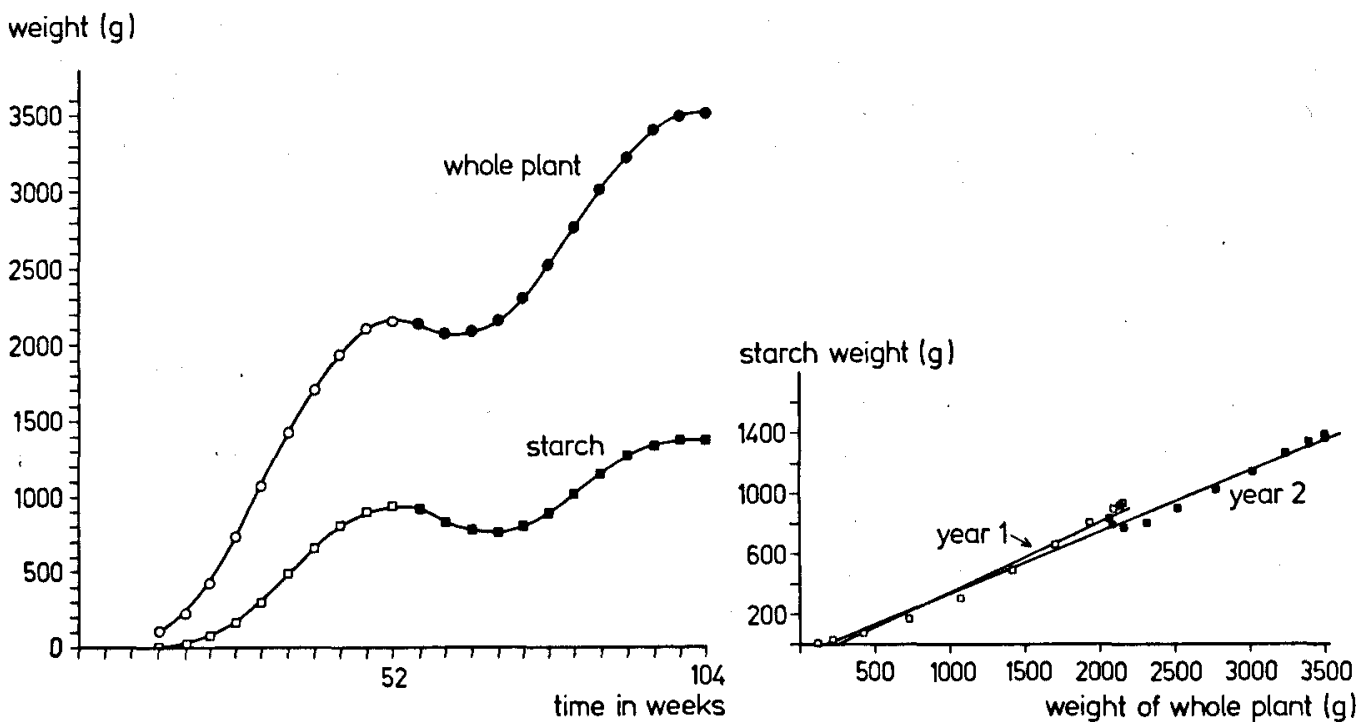

Fig. 3A (left). Relationship between plant age and dry weight of whole plant and between plant age and dry weight of starch, for means of 41 cultivars. (After Cours, 1951).

$\bigcirc$ and $\square$ weights for year $1 ; O$ and $\square$ weights for year 2 .

Fig. 3B (right). Relationship between dry weight of whole plant $x$ and dry weight of starch $y$, for means of 41 cultivars. (After Cours, 1951).

$\square$ for year $1: \mathrm{y}=0.47 \mathrm{x}-117 ; \mathrm{s}_{\mathrm{b}}=0.01 ; \mathrm{r}^{2}=0.98 ; \mathrm{n}=10$.

for year $2: \mathrm{y}=0.41 \mathrm{x}-68 ; \mathrm{s}_{\mathrm{b}}=0.01 ; \mathrm{r}^{2}=0.95 ; \mathrm{n}=12$. 


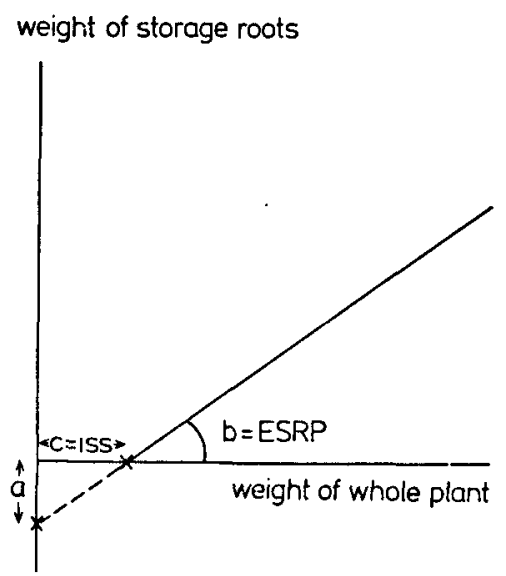

Fig. 4. Diagram of the relationship between dry weight of whole plant $x$ and dry weight of storage roots $y$, being of the form: $y=b x-a$. Regression coefficient $b=$ efficiency of storage root production = ESRP. ISS $=$ initial plant weight at which storage root proction starts.

\section{The model}

\section{Development of the model}

To describe the distribution of dry matter over storage roots of cassava, a simple model was developed. It was based ond the assumption that the relation between the weight of storage roots $\mathrm{y}$ and total weight $\mathrm{x}$ can be represented by the linear regression $y=b x-a$ (Fig. 4). In this relationship the magnitude of the regression coefficient b (Fig. 4) is quantitatively of great importance as it mainly represents the portion of carbohydrates that are diverted to the storage roots. In further discussion this coefficient will be called the efficiency of the plant at producing storage roots, or shortly the efficiency of storage root production (ESRP). It should not be overlooked that in the regression equation $y=b x-a$, y stands for storage roots; so in other words only plants of at least a few months old, with thickened roots are considered. The relationship between root weight and weight of whole plant in the very early stage of the growth cycle has not yet been determined.

The initial plant weight (ISS) at which storage root production starts (Fig. 4) is represented by the intercept with the $\mathrm{x}$ axic (c) and can be calculated according to $\mathrm{c}=\mathrm{a} / \mathrm{b}$; in which $\mathrm{a}=$ intercept with $\mathrm{y}$ axis. The stem cutting (planting material) forms part of ISS. Thus in order to know the actual increase in plant weight before storage roots start to produce, the weight of the stem cutting has to be subtracted from ISS.

It can easily be shown that as the plant grows older, the relative importance of $\mathrm{c}$ for the harvest index $\mathrm{HI}$, steadily decreases. $\mathrm{HI}$ is the part of the plant that is ultimately harvested. This part can be written as $\mathrm{HI}=\mathrm{y} / \mathrm{x}$. As $\mathbf{y}=\mathrm{bx}-\mathrm{a}$ it follows that $\mathrm{HI}=(\mathrm{bx}-\mathrm{a}) / \mathrm{x}$. If in the latter relationship $\mathrm{a}$ is substituted for $\mathrm{bc}$ it follows: $\mathrm{HI}=(\mathrm{bx}-\mathrm{bc}) / \mathrm{x}=\mathrm{b}(1-\mathrm{c} / \mathrm{x})=\operatorname{ESRP}(1-\mathrm{ISS} / \mathrm{x})$. Hence $\mathrm{HI}$ approaches ESRP as $\mathrm{x} \rightarrow \infty$. A plot of the function $\mathrm{HI}=\mathrm{b}(1-\mathrm{c} / \mathrm{x})$ is schematically shown in Fig. 5 and a plot of $\mathrm{HI}$ against weight of whole plant $\mathbf{x}$ as it was actually observed for the 112 plants in my field trial is shown in Fig. 6. Both 


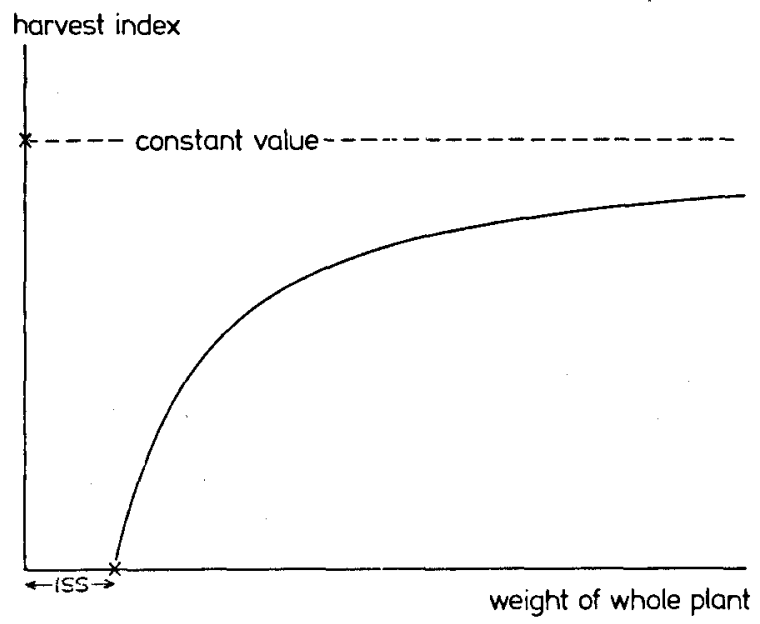

Fig. 5. Diagram of the relationship between dry weight of whole plant $x$ and harvest index $\mathrm{HI}$, being of the form: $H I=b(1-c / x)$. The initial plant weight at which storage root production starts $=$ ISS $=\mathrm{c}$.

figures show how harvest index reaches a constant value as the plant grows older. In fact this constant value $=$ ESRP.

\section{Application of the model to test genetic differences}

To investigate to what extent the distribution patterns are under genetic control, the literature was searched and results of Nijholt (1935), Cock (1973) and G. H. de Bruijn (pers. commun., 1977), who compared the growth of several cultivars, were recalculated. For each cultivar the specific equation for weight of storage roots $y$ with that of whole plant $x$, being of the form $y=b x-a$, was calculated. The $a$ and $b$ values found and additional information is shown in Table 1. An $F$ test for difference between the magnitude of the regression coefficients proved that the ESRP $(=b)$ value of $\mathrm{cv}$. SPP was significantly greater $(\mathrm{P}<0.05)$ than that for cv. Mangi. The same was true for cvs M-Colombia 22 and M-Colombia 113 compared with 16 other cultivars $(\mathrm{P}<0.05)$ and also for cvs Ta 25 and

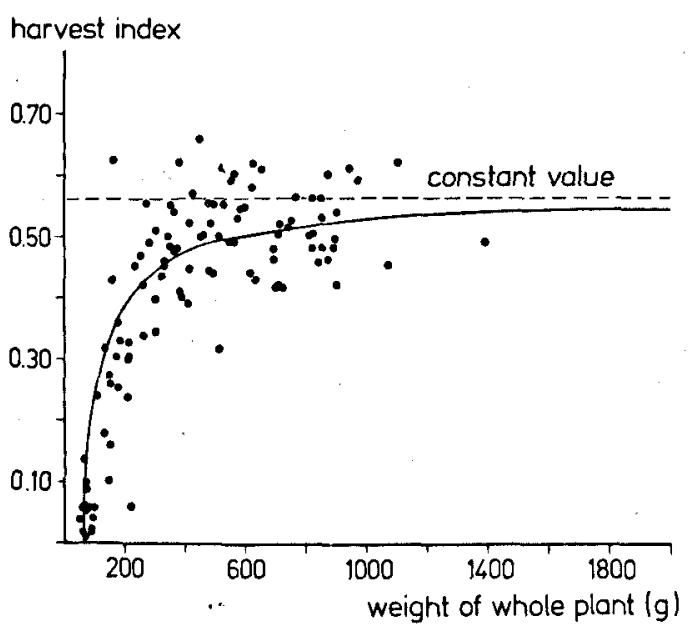

Fig. 6. The relationship found between dry weight of whole plant $x$ and harvest index $\mathrm{HI}$ for individual plants $(\mathrm{n}=112)$ of a field trial at UWI: $\mathrm{HI}=\mathbf{0 . 5 6}$ $(1-60 / x)$. 
MODEL OF DRY MATTER DISTRIBUTION IN CASSAVA

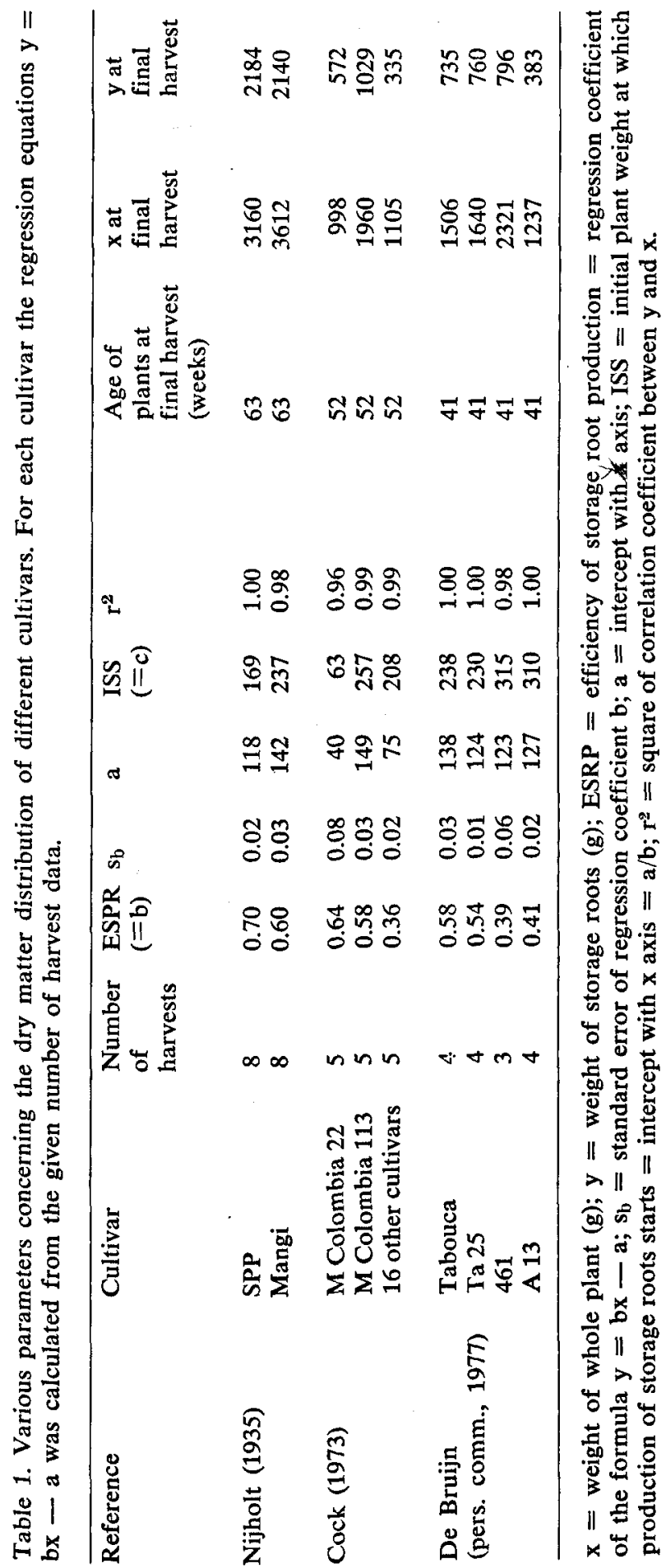


Tabouca compared with 'A 13' and '461' $(\mathrm{P}<0.01)$. There were also differences between ISS values; Cock's cv. M Colombia 22 for example, started to produce storage roots at a plant weight of $63 \mathrm{~g}$ whilst cv. M Colombia 113 started at a plant weight of $257 \mathrm{~g}$. However the true meaning of such a difference is not clear as the weights of stem cuttings were not specified and may have differed at planting time.

It goes without saying that differences in root yield y at final harvest between cultivars did not only depend on differences in the relation $y=b x-a$, but, as can be seen in Table 1, on differences between weights of whole plant $\mathrm{x}$ as well.

\section{Application of the model to test the effect of environmental conditions}

Distribution is also controlled by environment. For cassava this statement can be verified by the model, for example for temperature by recalculating the data of Hunt (1974). In an experiment in growth rooms, one group of plants was grown for 52 weeks at a high temperature $\left(29^{\circ} \mathrm{C}\right.$ day $/ 24^{\circ} \mathrm{C}$ night) and another group at a low temperature $\left(23^{\circ} \mathrm{C}\right.$ day $/ 18^{\circ} \mathrm{C}$ night). At the high temperature ESRP was significantly lower $(\mathrm{P}<0.05$; Table 2$)$ than at the low temperature. ISS was not affected.

Light intersity may have distinct effects as well. In a pot trial at UWI, I grew one group of plants at $100 \%$ normal light intensity and another at $20 \%$ normal light. Both groups were harvested only once, at 21 weeks after planting, and the regression equation was calculated from data of individual plants. The results

Table 2. Various parameters concerning the dry matter distribution at different environmental conditions. For each temperature the regression equation $\mathrm{y}=\mathrm{bx}-\mathrm{a}$ was calculated from the given number of harvest data. For high light intensity, $y=b x-a$ was calculated from data of 20 plants, and for low light intensity from data of 12 plants.

\begin{tabular}{|c|c|c|c|c|}
\hline \multirow[t]{2}{*}{ Parameter } & \multicolumn{2}{|c|}{ Data from Hunt (1974) } & \multicolumn{2}{|c|}{ Experiment at UWI } \\
\hline & $\begin{array}{l}\text { high temp- } \\
\text { erature }\end{array}$ & $\begin{array}{l}\text { low temp- } \\
\text { erature }\end{array}$ & $\begin{array}{l}\text { high light } \\
\text { intensity }\end{array}$ & $\begin{array}{l}\text { low light } \\
\text { intensity }\end{array}$ \\
\hline Number of harvests & 8 & 7 & 1 & 1 \\
\hline $\operatorname{ESRP}(=b)$ & 0.53 & 0.63 & 0.58 & 0.05 \\
\hline$s_{b}$ & 0.02 & 0.02 & 0.06 & 0.06 \\
\hline a & 35 & 41 & 7 & 2 \\
\hline ISS $(=c)$ & 66 & 65 & 12 & 40 \\
\hline $\mathrm{r}^{2}$ & 0.99 & 1.00 & 0.85 & 0.07 \\
\hline \multicolumn{5}{|l|}{ Age of plants at } \\
\hline final harvest (weeks) & 52 & 52 & 21 & 21 \\
\hline $\mathrm{x}$ at final harvest & 1420 & 870 & 176 & 125 \\
\hline $\mathrm{y}$ at final harvest & 753 & 522 & 95 & 5 \\
\hline
\end{tabular}

$\mathrm{x}=$ weight of whole plant $(\mathrm{g}) ; \mathrm{y}=$ weight of storage roots $(\mathrm{g}) ; \mathrm{ESRP}=$ efficiency of storage root production $=$ regression coefficient of the formula $y=b x-a ; s_{b}=$ standard error of regression coefficient $b ; a=$ intercept with $y$ axis; ISS $=$ initial plant weight at which storage root production starts $=$ intercept with $\mathrm{x}$ axis $=\mathrm{a} / \mathrm{b} ; \mathrm{r}^{2}=$ square of correlation coefficient between $y$ and $x$. 
are presented in Table 2 . The small number of plants ( 20 at normal light intensity and 12 at low light intensity) and the restricted variation in $\mathrm{x}$ explain the low values of $\mathrm{r}^{2}$. Nevertheless even this simple "experiment demonstrated that at low light intensity ESRP was significantly lower than at normal light intensity $(\mathrm{P}<0.001)$. The ISS values suggest that the plants grown at low light intensity reached a higher weight $(40 \mathrm{~g})$ before bulking started than the plants grown at normal ligt intensity $(12 \mathrm{~g})$.

The temperature and light conditions tested dit not affect only the dry matter distribution, but the growth of the whole plant as well ( $x$ values, Table 2).

In addition to light intensity and temperature, photoperiodicity has been related to dry matter distribution. Although data of Bolhuis (1966) and Lowe et al. (1976) were not complete enough to be tested by the model, their results imply that photoperiodic long days suppress the growth of storage roots and favour shoot growth. Water supply and mineral nutrition may have effects as well. However incompleteness of data in the literature do not allow any conclusion about these factors.

\section{Advantages of the model over harvest index and root-shoot ratio}

Until now harvest index (HI) has been commonly used to describe distribution over storage roots and other parts of the plant at a certain instant of time (= harvest time). However it is a great disadvantage that this parameter does not remain constant throughout time, whereas dry matter distribution does. Therefore it is preferable to use the function $y=b x-a$ (and thus of ESRP $=b$ and ISS $=\mathrm{a} / \mathrm{b}$ ) to describe the dry matter distribution.

It may make more sense to use the harvest index in crops other than cassava, for example cereals. For cereals, under given environmental conditions for a given genotype, HI has rather fixed values. For cassava, however, it is common practice to harvest the crop at any time between 6 and 24 monhts after planting and thus (roughly between 6 and 12 months) when HI may not have reached its constant value.

The literature showed that some results have been wrongly interpreted because the harvest index was considered only at a certain instant of time or at a certain total weight. For example if a factor enhances growth of the plant as a whole (increase of $x$, Fig. 5) without affecting ESRP, HI increases in the early stage of the growth cycle. Then it has often falsely been concluded that the formation of storage roots specifically was enhanced. This again demonstrates that it is desirable to calculate ISS and ESRP, rather than HI. If it is still required, HI can easily be calculated from ISS and ESRP at any weight of whole plant.

Some authors used the root-shoot ratio instead of HI. In general 'root' in this ratio means storage roots. If weight of storage roots and weight of shoot are plotted against each other, the straight line does not pass through the origin (storage root production starts only at a certain shoot weight), and thus the ratio does not remain constant. So the problem is similar to that with the use of HI and it is better not to use the root-shoot ratio.

It is of great importance to note that the parameters ERSP and ISS recom- 
mended above can be determined at an early stages of the growth cycle, i.e. roughly at about 6 months after planting. For this determination it may be sufficient to calculate $y=b x-a$ for individual plants of only one harvest. However to guarantee sufficient variation in $\mathrm{x}$, it is advisable to harvest more often, for example 3 or 4 times, after storage root production has started.

\section{Discussion}

Probably the distribution laws outlined here for cassava have been overlooked until now, because the weight relationships between storage roots and whole plant or between starch and whole plant, had not been tackled previously by regression. From the same data as depicted in Fig. 3A, Cours (1951) calculated the daily increase in the weight of root starch as a percentage of the daily increase in total dry weight. He found odd percentages at times when plants hardly increased in weight and overlooked a rather fixed distribution pattern when significant weight increase occurred. In fact by calculating the regression between whole plant and starch as I did, an unrealistic impression from a production point of view is avoided and a much better picture is formed of the quantitative distribution and of the part which will ultimately become starch.

The distribution of dry matter over shoot and storage roots, postulated to be lasting and constant, differs from crops such as sweet potato (Ipomoea batatas Lamb), potato (Solanum tuberosum L.) gladiolus (Gladiolus sp.), oninion (Allium sp.), dahlia (Dahlia Cav.) and others, in these crops shoot growth is suppressed when starch starts to accumulate in the storage organs. This difference may be related to the fact that cassava is a perennial crop that continues to grow for two or maybe three years. In addition once a young cassava plant has established, differentiation of new organs does not always take place. And if this does occur, for example by flowering or fruiting, these processes do not require much energy, because both flowers and fruits are small and not abundant.

It is evident that the validity of the model under field conditions hinges on the assumption that environmental conditions during growth do not vary to such an extent that dry matter distribution is noticeably altered. Although the effect of environment has been demonstrated, it seems reasonable to postulate, after analysing all the experiments, that under field conditions at normal population densities, the variations in environmental conditions do not cause deviation from linearity between weight of storage roots and that of whole plant. Moreover all field trials mentioned were carried out at different locations in the tropics.

Both physiologists and plant breeders may benefit from the fact that once production of storage roots has started, ISS and ESRP can be estimated with the model even in an early stage of the growth cycle. Until now HI (CIAT, 1975) has been a useful selection trait to test genotypes, but from model it is evident that ESRP should be preferred. It is still an open question whether ISS is under genetic control. To answer this, the (dry) weights of stem cuttings for all genotypes to be investigated must be similar at planting time. If genetic differences occur, ISS may become another useful selection trait. 


\section{Acknowledgments}

This work was done as a part of a research programme on root crops supported by the International Development Research Centre from Canada to the Faculty of Agriculture, University of the West Indies, St. Augustine, Trinidad. Financial support was also made available by the Netherlands Foundation for the Advancement of Tropical Research (WOTRO). The author wishes to thank Dr G. H. de Bruijn and Prof. J. A. Spence for valuable criticism and assistance.

\section{References}

Bolhuis, G. G., 1966. Influence of length of the illumination period on root formation in cassava, Manihot utilissima Pohl. Neth. J. agric. Sci. 14 (4) 251-254.

Brouwer, R., 1962. Distribution of dry matter in the plant. Neth. J. agric. Sci. 10 (5) (Special issue) 361-367.

CIAT, 1975. Annual Report Centro Internacional de Agricultura Tropical, CIAT, Apartado Aéro 67-13. Cali, Colombia, S.A., p. B1-B57.

Cock, J. H., 1976. Characteristics of high yielding cassava varieties. Expl. Agric. 12 (2) 135-143.

Cours, G., 1951. Le manioc à Madagascar. Mém. Inst. scient. Madagascar, Serie B, Tome III, Fascicule 2: 203-400.

Hunt, L. A., 1974. Growth physiology of Manihot. Internal Report, Department of Crop Science, University of Guelph, Guelph, Ontario, Canada, p. 1-66.

Lowe, S. B., J. D. Mahon \& L. A. Hunt, 1976. The effect of day length on shoot growth and formation of root tubers in young plants of cassava (Manihot esculenta Crantz). Pl. Sci. Lett. 6 (1) 57-62.

Nijholt, J. A., 1935. Opname van voedingsstoffen uit den bodem bij cassave. Landbouw (landbouwk. Tijdschr. Ned.-Indië) 10 (9) 329-353.

Sande Bakhuyzen, H. L. van de, 1937. Wetten bij den groei van tarwe en andere landbouwgewassen. Landbouwk. Tijdschr. 49: 885-900. 